\title{
SPRACHLICHE UND ETHNISCHE VERHÄLTNISSE IN UNGARNS LUTHERTUM AN DER WENDE VOM 16. ZUM 17. JAHRHUNDERT
}

\author{
ZOLTÁN CSEPREGI
}

\author{
Lutheran Theological University Budapest \\ zoltan.csepregi@lutheran.hu
}

\begin{abstract}
Ein besonderer Zug des Luthertums in Ungarn ist dessen ethnische Vielfalt. In der Studie wird der Frage nachgegangen, welche jene Volkssprachen sind, in denen Ungarns lutherische Geistliche um das Jahr 1600 ihre Gottesdienste feierten, predigten, sangen und schrieben. Wenn man aus den Quellen erhebt, mit welchen ethnischen Attributen die Prediger der mehrsprachigen lutherischen Kirchengemeinden damals bezeichnet wurden, kommt folgende Liste zustande: böhmisch, deutsch, kroatisch, polnisch, sächsisch, slowakisch, ungarisch und windisch. Wenn man also die Predigtsprachen zusammenzählt, könnte man (abhängig von der Zuordnung einzelner Dialekte) zu einer Zahl von 6 bis 8 Sprachen gelangen. Die Anzahl der liturgischen Sprachen ist hingegen viel geringer, denn diese standen bereits mit der Buchkultur und den Schriftsprachen in Verbindung. Liturgische Literatur (vor allem Agenden, Gebet- und Gesangsbücher, sowohl gedruckte als auch handschriftliche) stand nämlich nur in vier Sprachen zur Verfügung: Tschechisch, Ungarisch, Deutsch und Slowenisch. Für die Pfarramtskandidaten war es darum nötig, sich andere Volkssprachen anzueignen. Der Fremdsprachenerwerb geschah nicht mit schulischen Methoden, sondern in der Praxis, in der Umgebung von Muttersprachlern. Der hier unternommene Rundblick über Ungarns Luthertum vom Übermurgebiet bis zum Burzenland bezieht sich auf die Zeit um 1600. Die Mehrsprachigkeit war hier damals noch alltägliche Praxis, heute existiert sie jedoch nur noch als kulturelle Erinnerung und als weitestgehend untergegangene Tradition. Die Lutheraner konnten sich aber dank ihrer historischen Wurzeln doch eine besondere Offenheit und ein Verhalten gegenseitigen Respekts und gegenseitiger Annahme aus dieser Zeit herüberretten.
\end{abstract}

\section{Liturgische und literarische Sprachen, volkssprachliche Prediger}

In der kirchengeschichtlichen Literatur zählt die These zu den Axiomen, dass der lutherischen Reformation viel an den Volkssprachen lag. Obwohl die volkssprachliche Predigt bereits im Mittelalter gang und gäbe gewesen war, können die Liturgie, der Schulunterricht und der Buchdruck in Volkssprachen eindeutig mit den reformatorischen Bestrebungen in Zusammenhang gebracht werden.

Es darf als bekannt vorausgesetzt werden, dass in Ungarns ethnischer Vielfalt auch die reformatorische Botschaft in mehreren Sprachen erklang. Innerhalb der 
Konfessionen wurde aber dieser ethnische, sprachliche und kulturelle Pluralismus vor allem von der lutherischen Richtung beibehalten, während sich die reformierten und unitarischen Landeskirchen (von wenigen Ausnahmen und kurzlebigen Versuchen abgesehen) nur der ungarischen Ethnie verschrieben.

Obwohl hier bisher allgemein Bekanntes wiederholt worden ist, kann man jedoch auf überraschende Erkenntnisse kommen, wenn man die ethnische Karte der ungarischen Reformation aus der Nähe betrachtet. Die erste Frage dieser Studie lautet: Welche Volkssprachen genau sind es, in denen Ungarns lutherische Reformatoren einen Gottesdienst feierten, predigten, sangen und schrieben? Zweitens wird hier der Frage nachgegangen, inwiefern die modernen Stereotypien wie „Calvinismus ist eine ungarische Religion“ oder „Ungarns Lutheraner sind entweder Wenden oder Schwaben" auf das Reformationsjahrhundert selbst zutreffen.

Diese Fragen werden hier in einem Rundblick über Ungarn in einem Zeitausschnitt um das Jahr 1600 erörtert. Ich habe diesen Zeitpunkt in Ungarns Geschichte gewählt, weil der Prozess der Glaubenserneuerung bis dahin im Wesentlichen abgeschlossen war und sich die Konfessionen ausdifferenziert hatten (wenn auch nicht überall schon mit kirchenorganisatorischen Konsequenzen). Andererseits war die gewaltsame Rekatholisierung zu diesem Zeitpunkt noch nicht in Schwung gekommen, die im darauffolgenden Jahrhundert die Konfessionskarte Ungarns neu zeichnen sollte.

Wenn man anhand der vorhandenen Quellen erhebt, ${ }^{1}$ mit welchen ethnischen Attributen die Prediger der mehrsprachigen lutherischen Kirchengemeinden bezeichnet wurden (in einer sprachlich homogenen Gemeinschaft waren ja solche Beinamen nicht nötig), ergibt sich folgende Liste (in alphabetischer Reihenfolge): böhmisch, deutsch, kroatisch, polnisch, sächsisch, slowakisch, ungarisch, windisch. Die Attribute ,,deutsch, sächsisch, slowakisch, ungarisch“, die eindeutig auf Ungarns und Siebenbürgens Nationalitäten hinweisen, bedürfen hier gewiss keiner näheren Erläuterung.

Die Bezeichnungen „Böhme“ bzw. „böhmisch“ entstanden zumeist dadurch, dass sich die Slowaken der tschechischen Schriftsprache bedienten und dass dies auch auf ihre Bibelübersetzung, Agenden, Katechismen und Gesänge zutraf. Liest man also über eine ,böhmische“ Gemeinde, Kapelle, oder einen „böhmischen“ Gottesdienst in Ungarn, so ist darunter jeweils „slowakisch“ zu verstehen. Der Ausdruck „böhmischer Prediger“ ist hingegen schon differenzierter zu betrachten, denn unter den Slowaken Ungarns standen tatsächlich auch gebürtige Tschechen im Kirchendienst, vorwiegend diejenigen, die dann nach 1620 in die Emigration gezwungen worden sind. Aus diesem Grund ist nicht definitiv zu sagen, in genau welcher Sprache die Predigt damals tatsächlich erklungen sein mag: Sowohl für das Tschechische als auch für das Slowakische kann man sprachgeschichtlich und soziolin- 
guistisch sinnvoll argumentieren. ${ }^{2}$ Weil die Beantwortung dieser Frage weit mehr von den konkreten Personen und jeweiligen Orten abhängt als von der Sprache der Liturgie oder der Kirchengesänge, ist es gut vorstellbar, dass - einerseits durch Abstammung, Ausbildung und Überzeugung des Pfarrers, andererseits abhängig von den Ansprüchen und Traditionen der Gemeinde sowohl muttersprachlich-slowakische als auch hochsprachlich-tschechische Predigten gehört wurden.

Der Reformator der slawonischen Kroaten war Mihály Sztárai und auch unter den Wittenberger Studenten befanden sich manche Kroaten aus Slawonien und der Murinsel. Die Bezeichnung ,kroatischer Prediger“ bezieht sich aber nicht nur auf diese, sondern auch auf ihre Amtsbrüder in Westungarn, meistens auf dem Gebiet des heutigen Burgenlandes: in Güssing, Rechnitz, Schlaining, Deutschkreutz und Steinberg. ${ }^{3}$ Auch aus Ödenburg (SopronH) kamen Seelsorger zu den Kroaten in Kohlenhof (Kópháza H), wenn einer der Prediger zufällig Kroatisch konnte, wie der Körmender Gáspár Dragonus. ${ }^{4}$

Das Attribut ,,polnisch” ist in ähnlicher Weise zu hinterfragen wie die vorhin erwähnte Bezeichnung „,böhmisch“. Es kommt z. B. in Bartfeld (Bardejov SK) vor, wo man (wenn man nicht die Herkunft eines Predigers bedachte) die örtliche slowakische Gemeinschaft als passenden Sprachbezug heranzog (denn der Scharoscher Dialekt ähnelt sehr dem Polnischen). Dasselbe Attribut ,polnisch“ wurde aber auch in den 13 verpfändeten Zipser Städten und deren Zentrum Käsmark (Kežmarok SK) gebraucht, die jahrhundertlang zu Polen gehörten. Es ist gut vorstellbar, dass ,die polnischen Prediger“ im Käsmarker Schloss dem Hof und den Soldaten des Statthalters - sofern unter diesen Evangelische waren - wirklich auf Polnisch predigten.

Die Bezeichnung ,windisch“ konnte sich regionsabhängig auf Slowaken im Norden, auf Slowenen im Südwesten des Landes oder auf Kroaten in Slawonien beziehen. Über Letztere war bereits oben die Rede. Mit den „Wenden“ des Übermurgebiets (ein Endonym) und mit den ,Wenden“ der nördlichen Komitate (ein Exonym) wird sich unten je ein eigenes Unterkapitel beschäftigen.

Wenn man also die Predigtsprachen zusammenzählt, könnte man (abhängig von der Einordnung des Tschechischen und Polnischen) auf eine Zahl zwischen 6 und 8 gelangen, denn nicht einmal das Siebenbürgisch-Sächsische lässt sich ohne weiteres mit dem Deutschen gleichsetzen. Nach unseren Kenntnissen ließen die dialektalen Unterschiede in der Reformationszeit sogar nur ein beschränkt mögliches Verstehen zwischen diesen beiden Sprachgruppen zu.

Die Zahl der feststellbaren liturgischen Sprachen ist hingegen viel geringer, denn diese standen bereits mit der Buchkultur und den Schriftsprachen in Verbindung. Liturgische Literatur (vor allem Agenden, Gebet- und Gesangsbücher, sowohl gedruckte als auch handschriftliche) stand nur in vier Sprachen zur Verfügung: Tschechisch, Ungarisch, Deutsch und Slowenisch. ${ }^{5}$ 


\section{Das Verhältnis von Konfession und Volkssprache}

\section{Übermurgebiet}

In den Steuerverzeichnissen vom Raab-Mur-Kreis des Komitats Eisenburg sind eindeutig auf evangelische Geistliche hinweisende Einträge erhalten geblieben. 1599 gab es in 16 Dörfern, 1601 in 19 Dörfern evangelische Prediger (concionator), in Tišina zusätzlich auch einen Kaplan. ${ }^{6}$ Ihre Namen sind zwar nicht überliefert, aber es steht doch fest, dass um die Jahrhundertwende in den meisten im Mittelalter gegründeten Pfarren des Übermurgebiets bereits evangelische Pfarrer anzutreffen waren. ${ }^{7}$

In den Zentren des transdanubischen Kirchendistrikts, auf den Herrschaftsgebieten der Familien Nádasdy und Batthyány, begannen sich die reformierten und die lutherischen Richtungen erst in den 1590-er Jahren, sich in Lehre und Organisation auszudifferenzieren, und diese langsame Trennung hat zwanzig Jahre gedauert. Das von den Verwaltungszentren (Güssing, Csepreg, Sárvár, Pápa) entfernt liegende, größtenteils anderen Grundherren gehörende Übermurgebiet folgte diesen Ereignissen noch später.

Eine bewegte Episode der örtlichen Reformationsgeschichte war jene Epoche, als der reformierte Sprengel hier vorübergehend die Oberhand gewann. Die Calvinisten konnten in mehr als zwanzig Gemeinden eigene Seelsorger aussenden, die ein selbstständiges Seniorat bildeten. Dieser Prozess wird in der Historiographie traditionell mit einem Konfessionswechsel der Grundherren erklärt. Am Anfang des 17. Jahrhunderts bildete der Calvinismus in Ungarn tatsächlich eine relative Mehrheit, mit einem Schwerpunkt in der ungarischen Ethnie, und viele Adelige aus dem Übermurgebiet folgten tatsächlich dieser Richtung. In der Methodik von heute kann man aber nicht jede reformationsgeschichtliche Frage mit der Cuiusregio-Antwort abhaken, deshalb versuche ich im Folgenden eine eigene Erklärung, wobei ich einräume, dass jede örtliche Geschichte einzigartig ist, deren individuelle Situation und genaue Motivlage nicht mehr nachzuvollziehen sind.

Nach der Eroberung von Szigetvár durch die Osmanen 1566 zog sich die Bevölkerung des Komitats Somogy hinter die neue Grenzburg Kanizsa im Westen zurück, wobei die Bauern freilich weniger mobil waren als die Handwerker und die Kaufleute. Ihr Umzug verursachte in den Marktflecken und Dörfern des Übermurgebiets einen Madjarisierungsprozess, der sich allerdings nicht auf die kleineren slowenischen Dörfer erstreckte. Die Neuankömmlinge, zum Großteil ungarische Reformierte, bildeten eine Basis für die calvinistischen Prediger, ${ }^{8}$ die jedoch seitens der in kleineren Dörfern lebenden slowenischen Mehrheit keinen Rückhalt und keine Unterstützung erhielten und sich deswegen nicht lange halten konnten. Dieser Gegensatz drückt sich explizit in den Akten des sog. Kirchenprozesses von Martjanci aus. ${ }^{9}$ 
In den 1620-er Jahren unterzeichneten immer mehr reformierte Geistliche die Konkordienformel, d. h. sie unterstellten sich dem lutherischen Bischof, und dieser Bischof ordinierte immer mehr Wenden in Kirchenämter auf dem Übermurgebiet. Schließlich wurde dieser Wechsel 1627 durch eine lutherische Kirchenvisitation besiegelt. Zu jener Zeit wurden zehn Gemeinden visitiert und das erhaltene Visitationsprotokoll enthält neben dem kirchenhistorischen Sachverhalt auch sehr wertvolle wirtschaftsgeschichtliche und ethnographische Daten. ${ }^{10}$

Dass sich die Wenden über der Mur um 1600 des Krainer Dialekts des Slowenischen als liturgischer Sprache bedienten, ist abgesehen von diesbezüglichen Vermutungen nur durch zwei Quellen unterzumauern: Erstens listet das Visitationsprotokoll von 1627 neben anderen Büchern auch Luthers Hauspostille in Krainer Mundart auf (Lutheri Postilla Domestica Carniolica). ${ }^{11}$ Zweitens gab Johannes Manlius 1587 in Eberau eine Agenda Vandalica, d. h. eine windische Agende heraus, die heute leider als verschollen gilt. ${ }^{12}$ Der Druckort im Komitat Eisenburg und der Titel weisen darauf hin, dass das Werk für das Übermurgebiet bestimmt war. Anhand von Manlius` Laufbahn und fachmännischen Erfahrungen kann man es als sicher annehmen, dass die Agende im Krainer Dialekt fertiggestellt wurde, zumal Manlius vormals in Laibach als Drucker slowenischer Literatur in Erscheinung trat.

\section{„Slavonia”}

Im Wittenberger Ordiniertenbuch taucht manchmal der geographische Name Slavonia / Sclavonia auf, wobei er zu dieser Zeit noch nicht das zwischen Save und Drau gelegene Slawonien bezeichnete, sondern die in Nordwestungarn gelegenen Komitate Trentschin und Neutra, wo die Mehrheit der Bewohner Slowakisch sprach. ${ }^{13}$ Dieser eigenartige Namensgebrauch ist erstmals $1569 \mathrm{zu}$ belegen, als ausnahmsweise Käsmark aus der Zips zu Slavonia gehören wollte, 14 sein letzter Beleg stammt aus dem Jahre 1601.15 Diese geographische Vorstellung scheint danach aus der Mode gekommen zu sein.

Die im 18. Jahrhundert verbreitete Selbstbezeichnung von Intellektuellen und Bürgern unterschiedlicher Muttersprache im Königreich Ungarn als Hungari, also als Ungarländer, ${ }^{16}$ war im 16. Jahrhundert noch nicht selbstverständlich. So schrieb sich der Schulmann und Hebraist Nicolaus Colacinatus $(\uparrow 1583 / 84)$ aus dem mehrheitlich von Slowaken bewohnten Komitat Trentschin in die Wittenberger Matrikel nicht als Hungarus oder Pannonius, sondern als Slavus ein. ${ }^{17}$

Die meisten Städte im Nordteil des ungarischen Königreiches waren ethnisch gemischt, nur das prozentuale Verhältnis der deutschen, ungarischen und slowakischen Bevölkerung wechselte entsprechend der geographischen Lage und dem Lauf der Zeit. Diese Mehrsprachigkeit bedeutete, dass - wie oben gesagt - in den 
Kirchengemeinden deutsche, ungarische und slowakische Prediger, Diakone oder Kaplane angestellt wurden und je nach den örtlichen Verhältnissen die jeweiligen Minderheiten eventuell über ein eigenes Kirchengebäude oder eine Kapelle verfügten, wobei die städtische Kirchengemeinde eine einheitliche und gemeinsame Institution blieb. ${ }^{18}$ Wie ich weiter oben anhand des Attributs ,böhmisch“" erläutert habe, hat es sich herausgestellt, dass die auf die Kirchensprache und Prediger der Slowaken angewandte ethnische Bezeichnung in den Quellen nicht einheitlich ist, und dass es sich hier lohnt, auf diese Frage besonders einzugehen.

Die Slowaken und ihre Sprache heißen in den - gedruckten und archivalischen - Quellen um 1600 lateinisch $S$ (c)lavus oder $S$ (c)lavonicus, auf Deutsch ,windisch" und auf Ungarisch tót.${ }^{19}$ Dieselben Adjektive können zwar in anderen Gegenden z. B. für die Bezeichnung von Slowenen vom Übermurgebiet oder von Kroaten aus Slawonien gelten, aber Letzteres hat mit den Slowaken nichts zu tun. Falls es in den Quellen um Gottesdienste des örtlichen Slowakentums geht, finden sich meistens die obigen Wörter als Attribute zu den Begriffen wie Prediger, Kirchengebäude und Gemeinde.

Manchmal kommt zwar - wie oben dargestellt - in Zusammenhang mit Geistlichen auch das Wort ,böhmisch“ vor, das weist aber immer auf die Abstammung der genannten Personen hin, die man eben um ihrer tschechischen Muttersprache willen gern als Prediger unter Slowaken angestellt hat. In vier Fällen aber beziehen sich die lateinischen Adjektive Bohemus, Bohemicus unmissverständlich auf den kirchlichen Dienst und Gottesdienst und nicht auf die dabei wirkende Person selbst:

- Jacobus Schröter aus Neusohl (Banská Bystrica SK) wird 1580 in eine böhmische Kaplanstelle in Deutschliptsch (Partizanská Lupča SK) berufen; ${ }^{20}$

- die Obertrentschiner Kirchenordnung aus dem Jahre 1580 sieht vor, dass die Gläubigen am Gottesdienst auf Böhmisch singen; ${ }^{21}$

- 1616 und 1619 betonen zwei Schreiben, die Pfarrer- und Lehrerberufungen betreffen, die ungarischen und böhmischen Sprachkenntnisse der Kandidaten. ${ }^{22}$

Diese Daten unterstützen die Vermutung, dass - wie auch die Sprache der erhaltenen Agenden ${ }^{23}$ - die liturgische Sprache in den Gottesdiensten der Slowaken das Bibeltschechische (bibličtina) war. In diesem Fall muss um der genauen Bezeichnung willen von einem volkssprachlichen und nicht von einem muttersprachlichen Gottesdienst die Rede sein. ${ }^{24}$ Über das Problem der Predigt ist oben bereits das Wichtigste gesagt worden. 


\section{Transdanubien}

Der transdanubische Kirchendistrikt erstreckte sich um 1600 auf das Gebiet zwischen Donau und Plattensee, vorwiegend auf die Komitate Wieselburg, Ödenburg und Eisenburg, aber es gehörten auch Kirchengemeinden aus den benachbarten Komitaten Szalad, Weißbrunn und Raab dazu. Der Bruch zwischen den Konfessionen $\mathrm{AB}$ und $\mathrm{HB}$ wurde erst 1612, also erst nach der hier untersuchten kurzen Zeitphase vollzogen. Die westungarischen Bauern blieben vor allem durch die Autorität und Macht der Familie Nádasdy und besonders wegen deren traditioneller Rivalität mit den benachbarten reformierten Batthyánys im lutherischen Lager. Eine einzigartige Quelle für die vorliegende Untersuchung ist ein Exemplar des gedruckten Konkordienbuches mit den Unterschriften von 663 Pfarrern und Lehrern aus der Zeit von 1596 bis 1672 (sie befindet sich heute in der Széchényi Nationalbibliothek Budapest). ${ }^{25}$ Bis 1610 unterzeichneten hier 133 Personen die Konkordienformel, meistens frischordinierte Prediger, die keinesfalls theologisch undefinierbare Evangelische oder gar Katholiken waren, sondern eindeutig Lutheraner. Bei den Unterzeichnern wird manchmal kein bestimmter Pfarrer- oder Predigerdienst genannt, also kann es sich in solchen Fällen auch um Laien wie Schulrektoren handeln. Trotzdem habe ich diese Personen in die Untersuchung miteinbezogen, weil ihre spätere Beförderung in den geistlichen Dienst nicht nur möglich war, sondern sogar typisch, auch wenn die Quelle darüber schweigt.

Ich habe versucht, die Pfarrer nach ethnischer Zugehörigkeit und Muttersprache - anhand von Familiennamen, Herkunftsorten und Dienstorten - einzuordnen. In dieser Untersuchung, welche die Unterzeichner der Konkordienformel erfasst, bilden die Ungarn die bestimmende Mehrheit.

$\begin{array}{lr}\text { Ungarn } & 70 \% \\ \text { Deutsche } & 16 \% \\ \text { Slawen } & 10 \% \\ \text { Ungarn/Slawen } & 3 \% \\ \text { ungewiss } & 1 \%\end{array}$

Die „Slawen“ sind meistens Kroaten und Slowenen, die auf dieser lückenhaften Quellenbasis sehr schwierig von einander zu unterscheiden sind (Namen wie Belechich, Jagodich, Miholics, Musics, Ratkovicz, Tsebenich). Weil die ans Konkordienbuch angehängte Liste bis 1610 so gut wie keinen Ortsnamen aus dem Übermurgebiet enthält, ${ }^{26}$ könnten diese Südslawen eher westungarische Kroaten sein.

Unter den vier „Ungarn/Slawen“"verstehe ich Personen mit slowakischen Namen und slowakischen Geburtsorten, die in Transdanubien eindeutig einen unga- 
rischsprachigen Kirchendienst leisten mussten (Perich, Andreades, Stephanides, Havar). In die Gruppe der „Ungarn“ gehören madjarisierte Kroaten, wie Dianovits, Klaszekovits, Thokoych, Zvonarich, deren literarisches Werk entscheidend in der Beurteilung der Frage nach ihrer Muttersprache war. Die einzige Person, die sich sprachlich nicht einordnen lässt, ist ein nirgends sonst aufscheinender Mann namens Joannes Mallo.

Im alten transdanubischen Kirchendistrikt sind also neben einer ungarischen Mehrheit deutsche und kroatische Minderheiten anzutreffen. Dienstorte aus dem Übermurgebiet kommen auf der Liste bis 1610 überhaupt nicht vor. Nur der Geburtsort „Pusczini” deckt sich vielleicht mit dem heutigen Puconci in Slowenien. Die bescheidenen Erfolge der kroatischen Reformation sind oben bereits erwähnt worden. ${ }^{27}$ In den Konkordienformel-Unterschriften taucht der Ort Schützen in Ödenburger Komitat (Lövő H) auf, wo ausschließlich Prediger mit kroatischen Namen dienten (Belechich, Miholics, Musics). Wahrscheinlich war dies die einzige rein kroatische Kirchengemeinde in Transdanubien (neben den erwähnten, sprachlich gemischten Rechnitz, Schlaining, Güssing, Deutschkreutz und Steinberg), auf deren liturgische Sprache man aus den kroatischen Gesangsbüchern von Gregor Pythiraeus schließen kann. ${ }^{28}$ Mit der Region am linken Ufer der Donau (historisch „Oberes Donaugebiet“ genannt, die sich auf die Schüttinsel und das nördliche Flachland erstreckt) entwickelte sich eine eigenartige Wechselwirkung. Beide Gegenden verband besonders die gemeinsame Volkssprache, das Ungarische. Ziemlich viele Prediger bewegten sich zwischen den zwei Donauufern, d. h. sie bekleideten sowohl im Oberen Donaugebiet, als auch in Transdanubien kirchliche Ämter. ${ }^{29}$

\section{Oberes Donaugebiet}

Am längsten hielt sich nämlich das Miteinander von Lutheranern und Reformierten im Oberen Donaudistrikt, zu dem Gemeinden auf der Schüttinsel sowie am linken Donauufer gehörten und wo mehrheitlich ungarische Reformierte lutherische Oberhirten wählten, wenigstens so lange, wie die lutherische Familie Thurzó dort ihren Einfluss bewahren konnte. ${ }^{30}$

Zur friedlichen Trennung der zwei Konfessionen kam es hier in den 1610-er Jahren. ${ }^{31}$ In diesem Zusammenhang entstand ein den transdanubischen Konkordienformel-Unterschriften ähnliches Dokument, nach dem 69 Geistliche der Gegend zwischen 1614 und 1618 die Confessio Augustana Invariata unterzeichneten. ${ }^{32}$ Wenn man Familiennamen, Herkunftsorte und Dienstorte mit der vorhin dargestellten Methode untersucht, kommt man $\mathrm{zu}$ den folgenden Prozentsätzen: 


$\begin{array}{lr}\text { Ungarn } & 55 \% \\ \text { Ungarn / Slowaken } & 16 \% \\ \text { Slowaken } & 13 \% \\ \text { Deutsche } & 3 \% \\ \text { ungewiss } & 13 \%\end{array}$

Personen, die sich nicht einordnen lassen, tragen latinisierte Namen wie Davidis, Molitoris und Scripta, die bei mehreren Nationalitäten vorkommen, darüber hinaus sind ihre Herkunftsorte oder Dienstorte auch mehrsprachig. Kroatische Namen tauchen auch in rein ungarischen Kirchengemeinden auf (Dianovits, Radicz). Das einzige Beispiel aus dem Übermurgebiet, ein Jacobus Kothay aus Olsnitz (Murska Sobota SLO), gesellt sich zur ungarischen Fraktion.

Die Gruppe „Ungarn / Slowaken“ umfasst Geistliche, die durch ihre Familiennamen und Herkunftsorte mit der slowakischen Minderheit verbunden sind, die aber ihre Karriere in ungarischen Gegenden machten. Zu ihnen gehört der oben erwähnte Liptauer Michael Andreades, ordiniert in Sárvár, der in Ödenburg ein ungarisches, in Pressburg (Bratislava SK) aber ein ungarisch-slowakisches Predigeramt versah und der im ungarischen Milieu Andrásfy hieß; oder Michael Stephanides, der sowohl südlich als auch nördlich der Donau in ungarischen Dörfern, in Szopor und Csallóközkürt (Ohrady SK) Pfarrer war. ${ }^{33}$

Die absolute Mehrheit der „Ungarn“ ist somit auch im Oberen Donaugebiet bestimmend, aber an zweiter Stelle folgen hier nicht die „Deutschen“, sondern die „Slowaken“. Dieses ungarische Luthertum ist während der Rekatholisierung im 17. Jahrhundert fast spurlos verschwunden (denn nach der Aussterben der Familie Thurzó wurden hier die katholischen Esterházys die größten Grundherren); neben einigen ungarischen Predigerstellen in Stadtgemeinden wurde es nur noch durch manche Dörfer wie in Alsószeli und Felsőszeli (Dolné Saliby, Horné Saliby SK) vertreten.

\section{Gömör}

Zu den eingangs zitierten wohlbekannten Tatsachen gehört, dass man in drei Regionen des Königreichs Ungarn im Konfessionellen Zeitalter auf ungarischsprachige Lutheraner traf: in Westungarn auf der Kleinen Tiefebene, in Oberungarn im Komitat Gömör und im siebenbürgischen Burzenland. Aus diesen Regionen ist die Geschichte der Gömörer Lutheraner am wenigsten untersucht. ${ }^{34}$

Leider kann der bis 1735 selbstständige, einmal „Muraner“, dann wieder „Gömörer" genannte Kirchendistrikt keine solche umfangreiche Pfarrerlisten aus den Jahren um 1600 bieten, wie sie im Falle von Transdanubien und dem 
Oberen Donaudistrikt untersucht werden konnten. Es stehen jedoch die Muraner Artikel von 1590 und 1596 sowie die Gömörer Artikel von 1604 zur Verfügung, mit insgesamt 41 Unterschriften von 36 Geistlichen - wenn man die Laien nicht dazurechnet. ${ }^{35}$ Unter den Unterzeichnern ist kein ungarischer Pfarrer anzutreffen (nur unter den Laien gibt es ungarische Adelige: János Borbély, János Kisfaludi, János Bakos). Die erhaltenen Daten ordnen die überwiegende Mehrheit der Geistlichkeit den Slowaken zu - neben manchen Deutschen (Atzmann, Friedt, Radler, Schrötter), die vor allem in der Burg Muran (Muráň SK) sowie in den Bergstädten Dobschau (Dobšiná SK) und Rosenau ihr Amt versahen. Wenn man aus diesem Befund auf die Sprache der Kirchengemeinden schließen darf, kann man neben der slowakischen Mehrheit ${ }^{36}$ und der deutschen Minderheit von einem ungarischen Luthertum um 1600 keine Spur entdecken. ${ }^{37}$

Es ist bekannt, dass Gömör genau am Rande des ungarischen Sprachgebiets liegt und hier eben im 17. Jahrhundert eine ethnische Veränderung, nämlich ein rascher Madjarisierungsprozess vorging. Die Ursache war dem ähnlich, was ich vorhin über das Übermurgebiet geschrieben habe: Die osmanische Eroberung drängte einerseits die ungarische Bevölkerung der Tiefebene nach Norden, andererseits verlagerten sich die Märkte aus demselben Grund vom nördlichen Rand der Tiefebene in die Täler der Flüsse Rima und Sajó. Diese Zuwanderung erhöhte den Prozentsatz sowohl der Ungarn als auch der Reformierten in den Marktflecken und Kirchendörfern von Gömör und Kleinhont. Vermutlich nicht aus dogmatischer Ungewissheit oder grundherrlicher Willkür oder wegen der Wankelmütigkeiteines Geistlichen, sondern wahrscheinlich wegen der massenhaften Zuwanderung wechselten einige Gemeinden wie Alsóbalog und Uzapanyit in der Mitte des 17. Jahrhunderts vom lutherischen ins reformierte Lager. ${ }^{38}$ Der Rest der madjarisierten Dörfer ist aber, sofern sie die Rekatholisation überstehen konnten, lutherisch geblieben.

\section{Burzenland}

Wenn Gömör zuerst slowakisch-lutherisch war und erst später ungarisch-lutherisch geworden ist, verlief dieser Vorgang im Burzenland in der entgegengesetzten Richtung: Hier war die Bevölkerung ursprünglich ungarisch-reformiert, um in Laufe der Zeit ungarisch-lutherisch zu werden. Die betreffenden zehn Dörfer im Burzenland wurden, wie unten noch zu erläutern sein wird, erst im 17. Jahrhundert durch die Siebenbürger Sachsen zum Konfessionswechsel gezwungen. Erste Zeichen der Identitätsverschiebung tauchten bei den Siebenbürger Sachsen im 17. Jahrhundert auf. Bis zum Beginn des 17. Jahrhunderts störte es diese nicht, dass ihre ungarischen Leibeigenen, so etwa in den Dörfern im Burzenland, calvinistische Prediger holen ließen, meistens aus dem reformierten Kollegium 
in Strassburg am Mieresch (Aiud RO). Damals waren die Siebenbürger Sachsen noch nicht streng lutherisch und der Inhalt ihrer Kirchenordnungen über die Verwendung von Glocken, Orgeln und Bildern sowie gesäuertem und ungesäuertem Brot oder die Art der Beichte, Liturgie und Kirchengesänge exemplifiziert eher ein Vorherrschen des Kryptocalvinismus. ${ }^{39}$

Unter katholischen Fürsten bereitete ihnen die konfessionelle Heterogenität der Siedlungsgebiete der Siebenbürger Sachsen noch kein Problem. Als jedoch die reformierten Fürsten Gábor Bethlen (1580-1629) und besonders György I. Rákóczi (1593-1648) 1613 beziehungsweise 1630 den Thron Siebenbürgens bestiegen und sich für das Kirchenwesen und das Seelenheil der ungarischen Untertanen in den sächsischen Gebieten verantwortlich fühlten, änderte sich die Lage. Die Siebenbürger Sachsen freilich, die jegliche Einmischung in ihre autonomen Angelegenheiten vermeiden wollten, versuchten, sich an die theologischen Richtlinien der Zentren im Heiligen Römischen Reich anzupassen, die bereits durch die Konkordienformel bestimmt waren. Deren Prinzipien rechtfertigten den Anspruch der Siebenbürger Sachsen, die konfessionellen Verhältnisse in ihren autonomen Siedlungsgebieten zu homogenisieren.

Als erster Versuch ließ die Stadt Kronstadt (Braşov RO) zu Beginn des 17. Jahrhunderts die ungarischen Prediger des Burzenlandes auf die Augustana vereidigen und unterstellte sie dem sächsischen Superintendenten. ${ }^{40}$ Das beeinflusste aber den Inhalt ihrer Predigten gar nicht und die durch die Fürstenmacht ermunterten reformierten Pfarrerkandidaten verweigerten später immer öfter diesen Eid. Nach den erhaltenen Pfarrerlisten ${ }^{41}$ zu beurteilen, waren diese Geistlichen noch bis zur Mitte des 17. Jahrhunderts größtenteils Ungarn aus Siebenbürgen. Die Burzenländer Peregriner (und deren berühmtester, János Apácai Csere) waren ausnahmslos bestrebt, in reformierten Hochschulen zu studieren, und daraus kann man getrost auf den Konfessionsstand der Dörfer selbst schließen. ${ }^{42}$

Weil jedoch ihre eigenen Prediger der Aufgabe, den ungarischen Leibeigenen die ,rechte“ evangelisch-lutherische Lehre beizubringen, sprachlich nicht gewachsen waren, ließen sie theologisch zuverlässige slowakische Prediger aus dem Komitat Neutra holen, die das Ungarische beherrschten. ${ }^{43}$ Mit deren Hilfe konnte die Verbreitung der Calvinischen Lehren unter den Ungarn im Burzenland innerhalb einer Generation zurückgedrängt werden und die ungarischen Dörfer auf sächsischem Gebiet ohne Blutvergießen in die lutherische Landeskirche integriert werden.$^{44}$ So erlangte aus innenpolitischem Interesse anstelle der Priorität der Muttersprache nun die konfessionelle Zugehörigkeit die Vorrangstellung. ${ }^{45}$ Genauso wie es im Falle von Gömör dargestellt wurde, sind auch die Burzenländer nicht ursprünglich ungarische Lutheraner, um 1600 sind sie ja noch ungarische Reformierte. 


\section{Slowakische Reformierte? Die evangelische Union in Zemplin und Ung}

Dank seinem Senior, István Miskolci Csulyak, ist die Geschichte des Seniorats Zemplin und Ung in Nordostungarn um $1600 \mathrm{sehr}$ gut dokumentiert. Zu dieser Organisation gehörten sechs Jahrzehnte lang sowohl ungarische Reformierte als auch slowakische Lutheraner. Die Fachliteratur mag dieses gemeinsame Seniorat als eine frühe protestantische Union bezeichnen, ${ }^{46}$ obwohl die Quellen nicht verraten, ob es hier um ein freiwilliges oder gezwungenes Zusammenleben ging, ob diese Kooperation nur rein administrativer Natur war, oder ob sich auch in die Seelsorge in den Kirchengemeinden einmischte. Der Initiator dieses Zusammenschlusses kann der Grundherr gewesen sein, aber von einer Gewaltanwendung ist keine Spur zu entdecken. ${ }^{47}$

Im Visitationsprotokoll des reformierten Seniors springt 1611 ins Auge, dass man im nördlichen Teil des Sprengels, in der Gegend von Frönel an der Töpl (Vranov nad Topl'ou SK), lateinisch protokollierte, während die Daten aller anderer Kirchengemeinden auf Ungarisch erfasst worden sind. Aus dieser Beobachtung ist der logische Schluss zu ziehen, dass jene ungefähr zwanzig Mutter- und Tochtergemeinden nicht ungarisch, sondern slowakisch sein konnten. Die 1629er Visitation nennt hier auch einige Gemeinderäte, deren Namen mit geringer Ausnahme slowakisch sind. ${ }^{48}$ Schließlich hatte das Protokoll aus dem Jahre 1660 diese Gläubigen und ihre Pastoren eindeutig als „Lutheraner" und zum „Augsburgischer Bekenntnis" gehörig eingestuft ${ }^{49}$ - was den reformierten Senior doch nicht davon abhält, seine Visitation auch auf sie zu erstrecken. Laut Protokoll trugen die Geistlichen zum Teil eine Alba, zum Teil nicht..$^{50}$ Daraus kann man aber nicht auf eine sprachlich gemischte (ungarisch-slowakisch), sondern eine dogmatisch-liturgisch-konfessionell gemischte Organisation schließen ( $\mathrm{HB}-\mathrm{AB}$ ).

Im Marktflecken Frönel gab es zwei Kirchen, eine ungarische und eine slowakische, und der Pfarrer war immer der ungarische Geistliche, während sein slowakischer Kollege mit größerer Hörerschaft, aber niedrigerem Gehalt nur den Titel eines Kaplans führte.

Für die angebliche Union ist weder ihre Entstehung noch ihre Auflösung schriftlich genau festgehalten worden. Die Senioratssynoden behandelten die Frage nur insofern, als 1597 der Pfarrer von Frönel mit der Aufsicht der umliegenden slowakischen Gemeinden beauftragt wurde. ${ }^{51}$ Diese Maßnahme war wahrscheinlich sprachlich motiviert: Der im Süden residierende ungarische Senior konnte am ehesten vom Fröneler Pfarrer annehmen, sich mit seinen Nachbarn verständigen zu können.

Diese verordnete Praxis soll sich in der Mitte des 17. Jahrhunderts - laut Aussage einer einzigen Quelle - bereits auf einige slowakische Dörfer im benachbarten Unger Seniorat erstreckt haben, als seien inzwischen auch diese zu Mitglie- 
dern der Zempliner Union geworden. ${ }^{52}$ Die Bezeichnung „Union“ taucht zuerst in der Synode von 1662 auf und ebendieses Protokoll bewahrt die Ausscheidungserklärung der Lutheraner auf, ${ }^{53}$ die im nächsten Jahr ins Scharoscher lutherische Seniorat hinüberwechselten, um das (dann noch lange bestehende) ScharoschZempliner Seniorat zu gründen.

\section{Sprachkenntnis und Spracherwerb}

Im Folgenden stelle ich die frühesten Quellen darüber zusammen, dass Eltern ihre Söhne gezielt in anderssprachige Gebiete schickten, damit diese Fremdsprachen lernten, und dass das ungarländische Bürgertum - vor allem das deutschsprachige - das Ziel formulierte, mehrere Landessprachen zu erlernen. ${ }^{54}$ Diese Bestrebung ist reichlich belegt durch die in den Ordinationsmatrikeln aufbewahrten Autobiografien der ungarländischen Pfarrerkandidaten (siehe Anhang).

Unter den frühesten Daten springt zuerst der Lebenslauf von Jacobus Stenczll aus Neusohl ins Auge, der 1579 berichtet, sich der Türkengefahr zum Trotz das Ungarische in Rosenau aneignet zu haben. ${ }^{55}$ Dieselbe Gefahr wurde später von solchen Schülern betont, die um der ungarischen Sprache willen die Schule in Erlau (Eger $\mathrm{H}$ ) besuchten - noch unter ungarischer Herrschaft (die Festung und die Stadt fielen erst 1596). Ihre Sätze wollen andeuten, dass sie sich dem Spracherwerb zuliebe nicht einmal vor Opfer und Risiko scheuten. Der Ausdruck ,um einer Sprache willen"selbst liest sich aber erstmals 1588 in der Autobiografie des Michael Kawicky aus Priwitz (Prievidza SK), der ,um des Deutschen willen“ auf Anraten der Eltern hin nach Deutschproben (Nitrianske Pravno SK) in die Schule ging. ${ }^{56}$ Danach wiederholen und variieren die Pfarramtskandidaten diese Floskeln nur in den Ordiniertenbüchern.

Die beliebtesten Schulen für den ungarischen Spracherwerb waren Erlau (4 Vorkommnisse), Sárospatak (3), Wartberg (Senec SK, 2), Gönc (2), Frauenbach (Baia Mare RO, 2), Beregszász (Berehovo UA, 1), Debreczin (Debrecen H, 1), Eperies (Prešov SK, 1) und Rosenau (1). Dem Deutschen zuliebe wählten Slowaken die Schulen von Deutschproben und Schemnitz (Banská Štiavnica SK), während einzig der deutsche Stephanus Holtzmann-Xylander nach seinem Eperieser ungarischen Sprachkurs nicht das Böhmische, sondern das Slowakische(!) in Deutschliptsch und das Polnische im schlesischen Krappitz (Krapkowice PL) erlernen wollte. ${ }^{57}$

Dass der Fremdsprachenerwerb nicht mit schulischen Methoden, sondern in der Praxis, in der Umgebung von Muttersprachlern geschah, stellen die obigen Beispiele überzeugend dar. Dieser Schulwechsel und Schüleraustausch führte jedoch zu einem ernsten, prinzipiellen Problem, denn die aufgelisteten Gymnasien waren ausnahmslos humanistische Lateinschulen, denen am Kultivieren der 
biblischen und klassischen Sprachen viel mehr lag, als an der Entwicklung der volkssprachlichen Kompetenzen. Die Schule von Tarcal regelte diese Frage um 1600 folgendermaßen: „Der ertappt wird, seine Muttersprache zu gebrauchen, soll einen Denar pro Fall bezahlen, falls er aber von Rektor ertappt wird, bezahlt er 2-10 Denaren und lernt auswendig ein Gedicht von einem verdienten Dichter. Allerdings ist jeder berechtigt, mit einem Gastschüler der Sprachübung zuliebe auf seiner Muttersprache zu sprechen, sonst aber keinesfalls. ${ }^{658}$ Die Tarcaler Regel war gewiss kein Unikum, in allen Schulen der Epoche dürfte man in ähnlicher Weise verfahren haben. Und welche Gastschüler sind „um der Sprache willen“ nach Tarcal gekommen? Kaum Ungarn und kaum Türken. Die zitierten Sätze aus dem Schulgesetz einer kleinen reformierten Institution machen darauf aufmerksam, dass diese ungarischen Lehranstalten auch für die deutschen und slowakischen Lutheraner Nordungarns recht anziehend sein konnten.

Ein besonderes Charakteristikum am Luthertum Ungarns war dessen ethnische Vielfalt, gegenüber den dominant madjarischen Reformierten oder Unitariern, oder auch im Vergleich zu den reinen Nationalitätenkirchen der Griechisch-Katholiken oder Griechisch-Orthodoxen. Über die einstige Multiethnizität und liturgische Mehrsprachigkeit der Lutheraner zeugen heute meist nur noch die ererbten Familiennamen, und nur eine Handvoll Kirchengemeinden bietet den Kirchendienst parallel in mehreren Sprachen an. Die heute in Vergessenheit geratenen Minderheitssprachen sind heute nur noch rudimentär erkennbar, etwa in Form eigens zum Kirchengang angezogener Volkstrachten sowie in einigen liturgischen Traditionen deutschen oder slowakischen Ursprungs .

An der Wende vom 19. zum 20. Jahrhundert, als Ungarns politische Elite eine gezwungene Madjarisierung forcierte (Austausch von Ortsnamen, einheitliche Unterrichtssprache in den Schulen, ungarische Familiennamen), leistete die lutherische Kirche einen stillen Widerstand, sabotierte oft die gesetzlich vorgeschriebenen Maßnahmen und bewahrte sich ihre auf einer vielfaltigen Identität fußende tolerante Kultur. Mehrsprachigkeit war damals noch alltägliche Praxis (so korrespondierte die Kirchenleitung mit den Gläubigen auf drei Sprachen und die Pfarramtskandidaten studierten die Liturgik dreisprachig), heute aber - nach dem Friedensvertrag von Trianon, dem tschechoslowakisch-ungarischen Bevölkerungsaustausch und nach der Vertreibung der Ungarndeutschen - existiert sie nur noch als kulturelle Erinnerung und als untergegangene Tradition. Trotzdem scheint es, dass sich die Lutheraner dank ihrer historischen Wurzeln eine besondere Offenheit und ein Verhalten der respektvollen gegenseitigen Annahme aus diesen Tagen herüberretten konnten. 


\section{Abkürzungen}

AAV 2 = Album Academiae Vitebergensis. 2: 1560-1602. Niemeyer, Halle, 1894.

ELEM = Csepregi Zoltán: Evangélikus lelkészek Magyarországon. I: A reformáció kezdetétöl a zsolnai zsinatig (1610). I/1-3. MEDiT, Budapest, 2014-2016.

MEEE = Prónay Dezső - Stromp László (Hgg.): Magyar Evangélikus Egyháztörténeti Emlékek. I. Hornyánszky, Budapest, 1905.

MPEA = Magyar Protestáns Egyháztörténeti Adattár. 1-15. Magyar Protestáns Irodalmi Társaság, Budapest, 1902-1934.

$\mathrm{RMNy}=$ Borsa Gedeon et alii (Hgg.): Régi magyarországi nyomtatványok. 1-4: 1473-1670. Akadémiai, Budapest, 1971-2012.

RMSz = Wix Györgyné - P. Vásárhelyi Judit (Hgg.): Régi magyarországi szerzök: RMSZ. I: A kezdetektöl 1700-ig. OSZK, Budapest, 2008.

VD 16. = Verzeichnis der im deutschen Sprachbereich erschienenen Drucke des 16. Jahrhunderts. 1-25. Hiersemann, Stuttgart, 1983-2000. www.vd16.de

WO 1-2 = Buchwald, Georg: Wittenberger Ordiniertenbuch. 1-2: 1537-1572. Wigand, Leipzig, $1894-1895$.

WO JGPÖ = Buchwald, Georg: Beiträge zur Kenntnis der Evangelischen Geistlichen und Lehrer Österreichs aus den Wittenberger Ordinirtenbücher seit dem Jahre 1573. Jahrbuch für die Geschichte des Protestantismus in Österreich 16 (1895) 29-34, 176-202; 17 (1896) 25-63, $157-186$; 18 (1897) 56-72, 239-258; 19 (1898) 111-126; 21 (1900) 113-128; 23 (1902) 183203; 24 (1903) 78-96, 236-263.

\section{Literatur}

Bak, János M., 1993. Linguistic Pluralism in Medieval Hungary. In: Meyer, Marc Anthony, Hg. The Culture of Christendom. Essays in medieval history in commemoration of Denis L.T. Bethell. London: Hambledon Press, 269-279.

Bariska, István, 2000. Kísérlet egy menekülő népcsoport reformációjára. In: Vugrinec, Jože, Hg. Protestantizem - zatočišče izgnanih na Petanjcih (Nádasdyjev dvorec). Murska Sobota: SAZU, 193-204.

Benczik, Gyula et alii, 2008. Hgg. Források a Muravidék történetéhez = Viri za zgodovino Prekmurja. Szöveggyüjtemény = Zbirka dokumentov. 1. Szombathely-Zalaegerszeg: Vas Megyei Levéltár - Zala Megyei Levéltár

Binder, Pál, 1993. Az erdélyi magyar evangélikus egyházközségek és iskolák története és névtára, 1542-1860. [Ungarisch-Lutherisches Seniorat von Kronstadt]. Brassó.

Breznyik, János, 1883. A selmecbányai ágost. hitv. evang. egyház és lyceum története. 1-2. Selmecbánya: Joerges Ágost özv.

Csáky, Moritz, 1982. Die Hungarus-Konzeption. Eine „realpolitische” Alternative zur magyarischen Nationalstaatsidee? In: Drabek, Anna M., Plaschka, Richard G., Wandruszka, Adam, Hgg. Ungarn und Österreich unter Maria Theresia und Joseph II. Neue Aspekte im Verhältnis der beiden Länder. Wien: Österreichische Akademie der Wissenschaften, 71-89. (Veröffentlichungen der Komission für die Geschichte Österreichs 11.) Csepregi, Zoltán, 2017. Merkmale der lutherischen Reformation im Donau- und Karpatenraum vom 16. bis zum 19. Jahrhundert. Ethnische vs. konfessionelle Identitätsbildung, In: Schindling, Anton, Fata, Márta, Hgg. Luther und die Evangelisch-Lutherischen in Ungarn und Siebenbürgen. Augsburgisches Bekenntnis. 
Ethnie und Politik vom 16. Jahrhundert bis 1918. Münster: Aschendorff (Reformationsgeschichtliche Studien und Texte, im Druck).

Csepregi, Zoltán, 2015. A magyarországi iskolázás a reformáció századában (1540-1610). A wittenbergi ordinációs anyakönyvek tanúsága alapján. In: Szabó, Lajos, Hg. Teológia és oktatás. Az Evangélikus Hittudományi Egyetem oktatóinak tanulmánykötete. Budapest: Luther, 53-70.

Dienes, Dénes, Hg. 2001 Református egyház-látogatási jegyzókönyvek. 16-17. század. Budapest: Osiris (Millenniumi Magyar Történelem. Források).

Dienes, Dénes, 2008. Hg. Zempléni vizitációk 1629-1671. Miskolci Csulyak István zempléni esperes és hivatali utódainak feljegyzései. Sárospatak: Sárospataki Református Kollégium Tudományos Gyüjteményei (Acta Patakina 21.).

Dienes, Dénes, 2009. Református-evangélikus unió Zemplén vármegyében a 16-17. században. In: Kónya, Peter, Hg. „Nezamenitelné je dedičstvo otcov... “. Štúdie k dejinám a súčasnosti protestantizmu v strednej Európe k osemdesiatym narodeninám biskupa Jána Midriaka. Prešov: Prešovská univerzita, 171-177. (Acta Collegii Evangelici Prešoviensis 10.)

Fabó, András, 1869. Hg. Codex evangelicorum utriusque confessionis in Hungaria et Transsylvania diplomaticus $=$ A Magyar- és Erdélyországi mind a két vallású evangelikusok okmánytára . I. Pest: Osterlamm Károly.

Hain, Caspar, 1910-1913. Zipserische oder Leütschaverische Chronica vndt Zeit-beschreibung = Hain Gáspár Löcsei krónikája. 1-3. Lőcse: Szepesmegyei Történelmi Társulat.

Heltai, János: Müfajok és müvek a XVII. század magyarországi könyvkiadásában, 1601-1655. Universitas - OSZK, Budapest, 2008. (Res libraria 2.)

H. Hubert, Gabriella, 2015. A Martjanska pesmarica (Martyánci énekeskönyv) és a 16-17. századi magyar gyülekezeti énekek. In: Gáborjáni Szabó, Botond, Oláh, Róbert, Hgg. „Kezembe vészem, olvasom és arról elmélkedem”. Emlékkönyv Fekete Csaba születésének 75. és könyvtárosi müködésének 50. évfordulójára. Debrecen: Tiszántúli Református Egyházkerületi Gyüjtemények, 368-384. (A Tiszántúli Református Egyházkerületi Gyüjtemények kiadványai)

Iványi, Béla, 1990. A körmendi Batthyány-levéltár reformációra vonatkozó oklevelei. I: 15271625. Szeged: JATE. (Adattár XVI-XVIII. századi szellemi mozgalmaink történetéhez 29/1.)

Käfer, István, 2009. A Biblia a szlovák nemzeti művelődésben. In: Heltai, János, Hg. Biblia Hungarica Philologica. Magyarországi Bibliák a filológiai tudományokban. Budapest: Argumentum, 197-203. (A Magyar Könyvszemle és a Mokka-R Egyesület Füzetei 3.)

Käfer, István,2016. A keresztény Magyarország szlovák építőkövei - Pázmány Kalauzának szlovák fordításai. In: Maczák, Ibolya, Hg. Útmutató. Tanulmányok Pázmány Péter Kalauzáról. Budapest: MTA-PPKE Barokk Irodalom és Lelkiség Kutatócsoport, 205-208. (Lelkiségtörténeti tanulmányok 14.)

Katona, Tünde, 2011. Caritas und Memoria. Eine Leutschauer Stiftung im Dienste der Bildungsförderung in der Zips des 16. Jahrhunderts. München: Oldenbourg, (Buchreihe der Kommission für Geschichte und Kultur der Deutschen in Südosteuropa 41.)

Klaniczay, Tibor, 1993 Die Benennungen „Hungaria“ und „Pannonia” als Mittel der Identitätssuche der Ungarn. In: Klaniczay, Tibor, Németh, S. Katalin, Schmidt, Paul Gerhardt Hgg. Antike Rezeption und nationale Identität in der Renaissance insbesondere in Deutschland und in Ungarn., Budapest: Balassi, 83-100. (Studia humanitatis 9.)

Kónya, Annamária, Kónya, Péter, 2013. Szlovák reformátusok a XVI-XVIII. században. Sárospatak: Hernád.

Köblös, József, Kránitz, Zsolt, 2009. A Dunántúli Református Egyházkerület prédikátorai és rektorai. 1: 1526-1760. Pápa: Pápai Református Gyüjtemények. (A pápai református gyüjtemények kiadványai. Forrásközlések 10.) 
Kubinyi, András, 1986. Ethnische Minderheiten in den ungarischen Städten des Mittelalters. In: Kirchgässner, Bernhard, Reuter, Fritz, Hgg. Städtische Randgruppen und Minderheiten. Sigmaringen: Thorbecke, 183-199. (Stadt in der Geschichte 13.)

Kuzma, Dóra, 2014. Adalékok Besztercebánya 16. századi egyháztörténetéhez. In: Érfalvy, Lívia, Hg. A tudomány vonzásában. Evangélikus iskolák kutató tanárainak I. konferenciája. Budapest: Luther, 93-98. (Opera scholarum 1.)

Mikulik, József, 1917. A Gömöri Ág. Hitv. Evang. Esperesség története, 1520-1740. Pozsony: Wigand, (Magyar protestáns történelmi emlékek 2.)

Payr, Sándor,1910. Egyháztörténeti emlékek. Forrásgyüjtemény a Dunántúli Ág. Hitv. Evang. Egyházkerület történetéhez. I. Sopron: Dunántuli Ágostai Hitvallású Evangélikus Egyházkerület.

Payr, Sándor, 1924. A dunántúli evangélikus egyházkerület története. I. Sopron: Székely és Társa.

Šebjanič, Franc, 1977. Protestantsko gibanje panonskih Slovencev (Od začetkov reformacije do obdobja dualistične ureditve Avstro-Ogrske). Murska Sobota: Pomurska zalozba.

Šebjanič, Franc, 1978. The Protestant Movement of Slovenes in Pannonia. Murska Sobota: Pomurska zalozba.

Szabó, Előd, 2012: A „lutheránus” és a „kálvinista” egyház viszonya a XVII. században Dunántúlon. In: Horváth, Erzsébet, Literáty, Zoltán, Hgg. Történelmet írunk. Tisztelgő kötet Ladányi Sándor 75. születésnapja alkalmából. Budapest: Károli Gáspár Református Egyetem-L'Harmattan, 69-92. (Károli Könyvek. Tanulmánykötet.)

Szabó, Miklós, Tonk, Sándor, 1992. Erdélyiek egyetemjárása a korai újkorban, 1521-1700. Szeged: JATE. (Fontes rerum scholasticarum 4.)

Szegedi, Edit, 2008. Was bedeutet Adiaphoron - Adiaphora im siebenbürgischen Protestantismus des 16. und 17. Jahrhunderts? In: Wetter, Evelin, Hg. Formierungen des konfessionellen Raumes in Ostmitteleuropa. Stuttgart: Steiner, 57-74. (Forschungen zur Geschichte und Kultur des östlichen Mitteleuropa 33.)

Szende, Katalin, 2009. Integration through language. The multilingual character of late Medieval Hungarian towns. In: Keene, Derek, Nagy, Balázs, Szende, Katalin, Hgg. Segregation - Integration - Assimilation. Religious and Ethnic Groups in the Medieval Towns of Central and Eastern Europe. Farnham: Routledge, 205-234. (Historical Urban Studies)

Thury, Etele, 1998. A Dunántúli Református Egyházkerület története [1908]. I-II. 2. Aufl. Pozsony: Kalligram (Csallóközi Kiskönyvtár)

Wien, Ulrich A., 2010. Die Formierung des konfessionellen Raums in Siebenbürgen. Zur Wahrnehmung der Reformierten durch die siebenbürgisch-sächsischen Evangelischen im 16. und 17. Jahrhundert. In: Fata, Márta, Schindling, Anton, Hgg. Calvin und Reformiertentum in Ungarn und Siebenbürgen. Helvetisches Bekenntnis, Ethnie und Politik vom 16. Jahrhundert bis 1918. Münster: Aschendorff, 441-452. (Reformationsgeschichtliche Studien und Texte 155.)

Wien, Ulrich A., 2011. Wirkungen des Calvinismus in Siebenbürgen im 16. und 17. Jahrhundert. In: Dingel, Irene, Selderhuis, Herman J., Hgg. Calvin und Calvinismus: Europäische Perspektiven. Göttingen: Vandenhoeck \& Ruprecht, 127-153. (Veröffentlichungen des Instituts für Europäische Geschichte. Beihefte 84.)

Zoványi, Jenő, 1934. Protestánsok állítólagos uniója Zemplénben 1597-ben. Protestáns Szemle, 43, 226-228. 
Anhang: Ungarländische Pfarrerkandidaten über den Spracherwerb

\begin{tabular}{|c|c|c|}
\hline Name, Ordinationsjahr & Zitat & Literatur \\
\hline $\begin{array}{l}\text { Jacobus Stenczll } \\
\text { Nouosoliensis Panonius, } \\
1579\end{array}$ & $\begin{array}{l}{[\ldots] \text { in ciuitatem Rosnauiam }[\ldots]} \\
\text { ibi studui Vngaricam linguam sub D. } \\
\text { Martino Vnterbaum Tyropoliensi per vnum } \\
\text { annum. }\end{array}$ & $\begin{array}{l}\text { ELEM I/3: 198; } \\
\text { MEEE 55-56; WO } \\
\text { JGPÖ Nr. 133. }\end{array}$ \\
\hline $\begin{array}{l}\text { Michael Kawicky } \\
\text { Prividiensis Pannonius, } \\
1588\end{array}$ & $\begin{array}{l}\text { Hinc instinctu et suasu parentum meorum } \\
\text { contuli me discendae Germanicae linguae } \\
\text { gratia Pronam Germanorum, ubi vixi sub } \\
\text { Domino Andrea Schormanno annum cum } \\
\text { dimidio. }\end{array}$ & $\begin{array}{l}\text { ELEM I/1,803; MEEE } \\
\text { 92; WO JGPÖ Nr. } \\
329 .\end{array}$ \\
\hline $\begin{array}{l}\text { Isaacus Abrahamides } \\
\text { Hrochotius, } 1595\end{array}$ & $\begin{array}{l}\text { Egressus tandem [litterarum] necessariarum } \\
\text { pietatis linguarumque causa Schemnicium } \\
\text { primo sub Abrahamo Schremellio totum } \\
\text { quadriennium in studio literarum honeste } \\
\text { vixi. }\end{array}$ & $\begin{array}{l}\text { ELEM I/1: 3; MEEE } \\
\text { 112; RMSz 29; WO } \\
\text { JGPÖ Nr. } 458 .\end{array}$ \\
\hline $\begin{array}{l}\text { M. Stephanus Xylander } \\
\text { Leutschoviensis, } 1599\end{array}$ & $\begin{array}{l}\text { Postea vero ad linguas Slavonicam, } \\
\text { Hungaricam et Polonicam addiscere missus } \\
\text { Teutoliptoviam. }\end{array}$ & $\begin{array}{l}\text { ELEM I/3: 511; } \\
\text { MEEE 120-122; } \\
\text { RMSz 910; WO JGPÖ } \\
\text { Nr. 580. }\end{array}$ \\
\hline $\begin{array}{l}\text { Michael Pentekius } \\
\text { Zdanenus, } \\
1600\end{array}$ & $\begin{array}{l}\text { Hinc Schemnicium studiorum et linguae } \\
\text { Germanicae ediscendae causa profectus } \\
\text { Rectore M. Joanne Heinoldo annum cum } \\
\text { semestri usus sum. [...] Unde Ungarici } \\
\text { sermonis desiderio flagrans Agriam me } \\
\text { contuli ibique triennium sub scholae } \\
\text { praefectis Balthasaro Miscolcio et } \\
\text { Valentino Sarkozio exegi. }\end{array}$ & $\begin{array}{l}\text { ELEM I/2: } 263 ; \\
\text { MEEE 124-125; WO } \\
\text { JGPÖ Nr. } 612 \text {. }\end{array}$ \\
\hline $\begin{array}{l}\text { Nicolaus Marihowsky } \\
\text { [Marikowsky] } \\
\text { Belluschenus, } 1600\end{array}$ & $\begin{array}{l}\text { Sequentibus annis ueni Zemtzinum ad } \\
\text { discendam linguam Ungaricam, ubi } \\
\text { quinquennium consumsi, praeceptoribus } \\
\text { usus Valentine Zarnias, Daniele Köui et } \\
\text { Francisco Vasarhelino. }\end{array}$ & $\begin{array}{l}\text { ELEM I/2: } 28 ; \text { MEEE } \\
\text { 126, 133; WO JGPÖ } \\
\text { Nr. } 631 .\end{array}$ \\
\hline $\begin{array}{l}\text { Michael Guttowianus } \\
\text { Liptowiensis, } 1601\end{array}$ & $\begin{array}{l}\text { Traditus postea sum extraneis } \\
\text { praeceptoribus in superiorem Ungariam } \\
\text { ediscendae linguae gratia, ubi quoque } \\
\text { annos aliquot exegi, utpote Rivulis } \\
\text { dominarum mansi per biennium, } \\
\text { Berexasini et Goncini annum, Cassoviae } \\
\text { per duos annos, Agriae quae nunc occupata } \\
\text { est a Turcis, per biennium. }\end{array}$ & $\begin{array}{l}\text { ELEM I/1: 619; } \\
\text { MEEE 130; WO } \\
\text { JGPÖ Nr. } 663 .\end{array}$ \\
\hline $\begin{array}{l}\text { Daniel Corvinus } \\
\text { Wesselinus, } 1608\end{array}$ & $\begin{array}{l}{[\ldots] \text { anno } 79 . \text { Iglaviam propter germanicam }} \\
\text { linguam est promotus. }\end{array}$ & $\begin{array}{l}\text { ELEM I/1: 280; } \\
\text { MEEE 145. }\end{array}$ \\
\hline
\end{tabular}




\section{Noten}

1 Die unten dargestellten Daten sind zum Teil der jahrelangen Forschung am ungarischen Pfarrerbuch (Evangélikus lelkészek Magyarországon = ELEM) und teils auch den elektronischen Suchmöglichkeiten im Ungarischen Lutherischen Digitalen Archiv (Magyar Evangélikus Digitális Tár $=$ http://medit.lutheran.hu) zu verdanken.

2 Dieselbe Spannung besteht zwischen dem Frühneuhochdeutschen und dem siebenbürgischsächsischen Dialekt wie auch zwischen dem Krainer Slowenischen und der windischen Mundart des Übermurgebiets, aber auch zwischen jeder Hochsprache und deren örtlichen Dialekten. Die funktionale Linguistik kennt eine bewusste Unterscheidung der „heiligen” und „profanen” Spracharten. Diese Gegenüberstellung konnte auch durch das Außenstehen des Geistlichen betont sein, der meist kein Ortskind war, sondern oft weit aus der Ferne kam. Die Gläubigen erwarteten es nicht nur keinesfalls, sondern fanden es sogar anstößig, in den Mauern der Kirche anstatt eines gehobenen Stils ihre alltägliche Mundart zu hören. Dieser Auffassung und dieser Tradition entgegen formierte sich von Zeit zu Zeit das Programm der „muttersprachlichen” Liturgie und Predigt als Erneuerungsbestrebung, d.h. der Einzug der Alltagssprache in den Kirchenraum. Auf dieses Problem geht István Käfer in seinen Arbeiten sehr genau ein (Käfer 2009; Käfer 2016).

3 Payr 1910, 37, 45, 150; Iványi 1990, 203-204; Bariska 2000.

4 Payr 1910, 37; Payr 1924, 21; ELEM I/1: 394.

5 Heltai 2008, 82; Csepregi 2017; Hubert 2015. Die einzelnen Beispiele aus RMNy siehe unten.

6 MPEA 7: 104-107.

7 Payr 1910, 62, 110-111, 120; Payr 1924, 258, 263, 607; Köblös - Kránitz 2009, 431, 592; Benczik 2008, 133-135 (Nr. 46); ELEM I/1: 761; I/3: 253-254.

8 MPEA 8: 23-24, 31, 52, 54-55, 73.

9 Thury 1998, I: 354-369; Payr 1924, 236-267; Šebjanič 1977, 21-24; Šebjanič 1978, 12-14; Benczik 2008, 152-153 (nr. 55); Köblös - Kránitz 2009, 61-62; Szabó 2012, 69-92.

10 Payr 1910, 102-128; Šebjanič 1977, 17-21, 27; Šebjanič 1978, 10-12, 15-16; Benczik 2008, 132-135 (Nr. 45-46).

11 Payr 1910, 120; Benczik 2008, 133-135 (Nr. 46).

12 RMNy Nr. 597A.

13 Vgl. die Eintragung von Joannes Lazyczkius Pannonius (1587): Interea Prividiensi schola, cui praefuit Doctissimus vir Albertus Hussellius, in nostra Slavonia tum celeberrima facta [...]. WO JGPÖ 18 (1897), 65 (Nr. 306); MEEE 90; Georgius Crinaceus de Brodek (1588): Deinde contuli me in Schlavoniam in oppidum Bischae, vbi versatus sum sub R. V. domino Nicolao Baciceo Arvensi [...]. WO JGPÖ 18 (1897), 68 (Nr. 319). Siehe weiter: WO JGPÖ Nr. 170, 317, $353,510,649$.

14 WO 2: Nr. 907: prophectus in Schlavoniam Tiropolie sub Praeceptore D. Richardo.

15 WO JGPÖ Nr. 649.

16 Die Hungarus-Konzeption ist ein von dem Literaturhistoriker Tibor Klaniczay (1923-1992) geprägter Begriff. Vgl. dazu Klaniczay 1993. Ausgearbeitet wurde die These von Moritz Csáky (Csáky 1982).

17 AAV 2: 161 (1569): der in Klače geborene Colacinatus hat danach ungefähr anderthalb Jahrzehnt lang verschiedenen Schulen Ungarns vorgestanden (RMSz 145). Der 1584 in Wittenberg eingeschriebene Hieremias Sartorius aus Veličná war ebenfalls ein Slavus (AAV 2: 320; RMSz 700). Es haben sich auch als Sclauus vorgestellt die in Wittenberg ordinierten Martinus Holecius aus Oslany, Alexander Zielinus aus Sillein und Nicolaus Haras aus dem Komitat Trentschin: WO 2: Nr. 141, 799; WO JGPÖ Nr. 502; MEEE 115; ELEM I/1: 650, 705.

18 Kubinyi 1986; Bak 1993; Szende 2009. 
19 MPEA 2: 6-9, 11-13, 15-16, 18, 59, 79, 82; MPEA 7: 9; Breznyik 1883, 1: 35-37, 39, 46, 48, 71, 210, 216, 218, 288, 291, 298, 301, 323, 333-334, 350; Hain 1910-1913, 278; Katona 2011, 142, 275, 298, 309; Kuzma 2014, 95. Diese Daten stammen aus Neusohl und Schemnitz, sowie aus Leutschau und den Protokollen der Fünfstädte, schließlich aus den Muraner und Oberpoprader Artikeln. Vgl. RMNy Nr. 1033(47), 1632(11).

20 WO JGPÖ 17 (1896), 47 (Nr. 156): oblata est mihi uocatio [...] Ecclesiae Lipschensis ad munus ecclesiasticum loco sacellani Boemici. Die Muraner Artikel schreiben 1590 trotzdem ein ,slowakisches Singen” im Gottesdienst vor, , dieselben nennen 1596 auch den Katechismus „slowakisch”, obwohl dessen erhaltene Stücke eindeutig auf „Bibeltschechisch” geschrieben worden sind. MPEA 2: 17-18, 59; RMNy Nr. 479.

21 MPEA 7: 28: Ubi autem desunt docti scholastici, canantur omnia Bohemicae [!] vel piae cantiones de temporibus.

22 MPEA 15: 212, 239.

23 Bibeltschechisch = ,slowakisch": RMNy Nr. 479, 564 (Katechismus, Gebete und Gesänge, nur sehr fragmentarisch erhalten), App. 95, 104, Nr. 1594 (Katechismus, Gebete und Gesänge), Nr. 1632, 1655 (Tranoscius' Gebet- und Gesangbuch).

24 Die Muraner Artikel schreiben aber 1590 eindeutig vor, dass das Abendmahl in der slowakischen Volkssprache ausgeteilt werden soll, damit jeder verstehe: nec in administratione sacramentorum alia, quam vulgari sclavonica utatur lingva, eaque clare et distincte, ut omnes audire intelligereque possint. MPEA 2: 16. Ist es möglich, dass sich dieser Satz nicht auf das gesprochene Slowakische, sondern auf die tschechische Literatursprache als Volkssprache bezieht? Oder kann man hier eine geographisch geteilte Praxis annehmen, wonach man sich auf den mehr urbanisierten Gebieten der mährischen Grenze entlang eher einer tschechischen und mehr südlich, in der ländlichen Gegend am Rande des ungarischen Sprachgebiets, eher einer slowakischen Liturgie bediente?

25 Concordia. Pia et vnanimi consensv repetita confessio fidei et doctrinae electorvm, principvm, et ordinvm imperii, atque eorundem theologorum, qui Augustanam confessionem amplectuntur et nomina sua huic libro subscripserunt. [...] Leipzig, Steinmann, 1580. VD 16. K 2005. Széchényi Nationalbibliothek Budapest, Handschriftenabteilung, Quart. Lat. 1177; die Unterschriften sind abgedruckt: Payr 1910, 52-99.

26 Nur der Geburtsort „Pusczini” deckt vielleicht das heutige Puconci in Slowenien (Payr 1910, 58). Dienstorte aus dem Übermurgebiet kommen auf der Liste bis 1610 überhaupt nicht vor.

27 Die Forschung erklärt dieses Scheitern in der Regel mit dem Umstand, dass die Kroaten bereits vor der Reformation eine verständliche, volkssprachliche Liturgie (die auf den altslawischen Ritus von Method zurückging) gehalten haben - ein Sonderfall in der Westkirche!

28 RMNy Nr. 982, 1021. Vgl. ELEM I/2: 365.

29 ELEM I/1: 337, 339, 707-708; I/2: 227, 235; I/3: 123, 202.

30 Thury 1998, I: 123-158; Köblös - Kránitz 2009, 45-49.

31 Fabó 1869, 123-136; Thury 1998, I: 405-407.

32 Fabó 1869, 102-105.

33 ELEM I/1: 43.

34 Bei diesen kann - ähnlich wie im Burzenland - außer den unten schilderten Prozessen eine lutherische Mission durch die örtlichen Grundherren, d. h. die oberungarischen deutschen Bergstädte Rosenau, Göllnitz, Schmöllnitz (Rožňava, Gelnica, Smolník SK) usw. angenommen werden.

35 MPEA 2: 15, 21-22, 68-71, 117.

36 Beide Varianten der Muraner Artikel (1590 und 1596) sprechen konsequent über „Slowakisch” (Slavonica lingua; slavice), als es um eine Liturgie, ein Singen oder einen Katechismus in der Volkssprache geht: MPEA 2: 16-18, 59. 
37 Der erste bekannte ungarische Prediger, der oben erwähnte Jacobus Kothay, ist 618 zum Hofprediger des Gömörer Obergespans, György Széchy geworden (Fabó 1869, 105), später taucht derselbe als lutherischer Senior in Nižný Blh auf (Mikulik 1917, 53, 61-62). In der Umgebung der Familie Széchy sind ab 1621 ungarische Kaplane der Burg Muran anzutreffen. Zur selben Zeit gab es in Rosenau auch eine ungarische Predigt, die von einem das Ungarische beherrschenden Kaplan gehalten wurde, aber diese Kaplane trugen nicht alle einen ungarischen Namen (MPEA 2: 117).

38 Mikulik 1917, 74-76.

39 Szegedi 2008, 63-64; vgl. Wien 2010; Wien 2011.

40 Binder 1993, 15-16, 110-111.

41 Binder 1993, 112-140.

42 Binder 1993, 141; Szabó - Tonk 1992, Nr. 759, 1265, 1740, 2783 (Geist: 1648; Kriesbach: 1647, 1698; Langendorf: 1673).

43 Lucas Prividiensis: ELEM I/2: 354. Sowie Georgius Szeli und Michael Matthaeides.

44 Binder 1993.

45 Csepregi 2017.

46 Zoványi 1934; Dienes 2009; Kónya - Kónya 2013, 169-174.

47 Dienes 2009, 173-174; Kónya - Kónya 2013, 170.

48 Dienes 2008, 7-65. Die hier protokollierte vernichtende Kritik des Pfarrers von Parchovany über seine Gläubigen spricht für sich: vocavit eos pogányszki. Dienes 2008, 39. Das Epistolar von István Miskolci Csulyak nennt 1633-1635 diese Prediger und Gemeinden schon eindeutig: Slavonici. MPEA 11: 186-187; 12: 215.

49 Dienes 2008, 112-113, 274-275; Dienes 2009, 172.

50 Dienes 2008, 30; Kónya - Kónya 2013, 149.

51 Zoványi 1934, 226; Dienes 2009, 173. Zu dieser Zeit war der slowakische Andreas Mednensky Pfarrer in Frönel, ein Schwiegersohn vom Bibelübersetzer Caspar Károlyi, späterer Senior in Zemplin (ELEM I/2: 54). Während der Zeit seiner Nachfolger kam es zur Arbeitsaufteilung, dass der Pfarrer in Frönel ungarisch war und dessen slowakischer Kaplan als Konsenior den umliegenden Gemeinden vorstand. Das führte oft zu Dependenzstreiten und Prestigekämpfen. MPEA 13: 139.

52 Dienes 2001, 254; Dienes 2009, 175; Kónya - Kónya 2013, 173-174.

53 Dienes 2009, 174.

54 Unter „Landessprachen“ (linguae patriae) verstanden die Pfarrerkandidaten mindestens drei Sprachen, nämlich Ungarisch, Deutsch und eine der in Ungarn gesprochenen slawischen Sprachen wie Slowakisch, Kroatisch, Serbisch oder Slowenisch, die regional wechselten. Vgl. die Ausdrücke causa Slavonismi, Hungarismi gratia (1716); linguae patriae causa (1731): MEEE 193, 206.

55 WO JGPÖ Nr. 133; MEEE 55.

56 WO JGPÖ 18 (1897), 71 (Nr. 329); MEEE 92: discendae Germanicae linguae gratia.

57 WO JGPÖ 24 (1903), 90 (Nr. 580); MEEE 120: ad linguas Slavonicam, Hungaricam et Polonicam addiscere.

58 MPEA 11: 167: Qui nativo sermone licenter loqui ab aliquo deprehensus fuerit, pro singulis erratum numum, si a Rectore, duos, aut decem pendito, versus probati autoris expedite recitato; cum peregrino interea linguae discendae gratia unicuique potestas nativo sermone loquendi conceditur, secus non. 